Sport Humanities

\title{
The experience of athletes with disabilities in mainstream sports: an interpretative phenomenological analysis
}

\author{
Jônatas Augusto Cursiol (D), Cristiano Roque Antunes Barreira \\ Universidade de São Paulo, Escola de Educação Física e Esporte de Ribeirão Preto, Ribeirão \\ Preto, SP, Brasil.
}

Associate Editor: Giselle Helena Tavares, Universidade Federal de Uberlândia, Uberlândia, MG, Brazil.

\begin{abstract}
Aim: Through reports of the athletes with disabilities interviewed, this study aimed to understand how the experiences lived in mainstream sports occur among people without disabilities. Methods: Husserl's classic phenomenology was the methodological framework adopted. The phenomenological interview was carried out with an intentional sample that included six athletes with some type of physical disability and later its recording was transcribed for the procedures of phenomenological reduction and intentional crossing to explain the meaning of what is experienced by these athletes in mainstream sport. Results: Five categories essentially describe how these experiences occur: operational body barred in the world; shaping the movement; the invisibility of disability; determination stimulus; and normalization of social relations in mainstream sports. These experiences correspond to a dynamic process in which each part does not necessarily follow the other. Conclusion: The experience in mainstream sports allowed the interviewees to improve their experience of capacity, self-efficacy, and recognition through the mutuality between self-perception and the expectation of acceptance by society.
\end{abstract}

Keywords: physical disability, integrated sport, phenomenology, lived experiences.

\section{Introduction}

The present study is the result of the concern felt by one of the researchers for living and playing sports over the years among people with physical disabilities, in a context in which there is no adaptation to the rules. In the first place, the integrated sports practice with people with disabilities can cause some estrangement, exaggerated care, because the bodily admiration in the sport represents a significant characteristic and the ability is typically associated with a perfect body, which is a social construction that can infer that disability is something negative ${ }^{1}$. Nonetheless, when perceiving the positive view of disability, as a new organization with its laws, a novel way of being in the world with its values ${ }^{2}$, at each training session or competition, this excess of care and fear of injuring players with disabilities seem to tend to oblivion. However, how do they feel? How important is this practice to them?

Comprehending the differences between integrating and including are important for a better understanding of the dynamics of participation of athletes with disabilities in mainstream sports. According to Kamberidou, Bonias, and Patsantaras ${ }^{3}$, the word "integrate" means to change, remedy or modify the person or the context for an individual or group to join another individual or group, so that they fit into and be absorbed in the existing system. On the other hand, Sassaki ${ }^{4}$ suggests that "including" implies modifying society through changes in physical and social environments. Swain and French ${ }^{5}$ argue that through inclusion, the culture of disability is recognized from their experiences, the disabling barriers are removed and needs related to the disability are met. Essentially, whereas people with disabilities adapt their condition to mainstream sport, sports for people with disabilities have their adaptations designed according to the athlete's disability condition.

In the history of the Olympic sport, some cases of athletes with disabilities who participated in competitions with athletes without disabilities were highlighted. This is the case of the North American runner Marla Runyan, the first legally blind athlete to compete in the Olympic Games ${ }^{6}$, and of two other athletes who competed in both the Olympic and Paralympic Summer Games in London, 2012. They are the Polish tennis player Natalia Partyka, born without a fully developed forearm, who in the Olympics reached the round of 16 in the single's category, and the South African sprinter Oscar Pistorius, known as "Blade Runner" for using thin prostheses made of carbon fiber in the place of his lower limbs, semi-finalist of the 400-meter race and the finalist of the 4 x 400-meter relay with the South Africa team ${ }^{7}$. Nevertheless, Richard, Issanchou, and Ferez ${ }^{8}$ argue that Pistorius' participation in 
mainstream sport was controversial due to the impossibility of concluding whether or not he gained an unfair advantage over athletes not assisted by technology. Therefore, due to the possible technological advantages brought about by his prostheses, which would hurt the traditional view of Olympic justice, the case of Oscar Pistorius stimulated debate regarding human improvement in sport, even if he had never won a major sporting event competing against athletes without disabilities ${ }^{8}$.

Despite their physical disabilities, athletes like Natalia Partyka and Oscar Pistorius have sought to be part of the sports environment aimed at people without disabilities, where, according to Hughes and Paterson ${ }^{9}$, they can be excluded due to construction regulations. Such constructions disregard the phenomenological concept of corporeality explained by Standal ${ }^{10}$, which says we are our bodies, which in turn are a new perspective on a world where inclusion remains, nevertheless, a considerable challenge. As argued by Van Hilvoorde and Landeweerd ${ }^{6}$, the prominence obtained by these athletes in mainstream competitions can contribute to the denaturalization of the view that people with disabilities have in sports, which frequently refer to patients fighting their limitations instead of athletes with specific and exceptional talents.

In light of Salamon-Krakowska ${ }^{11}$ thoughts, athletes with disabilities can carry out with their bodies meaningful experiences and interactions with people who are different from themselves through training and deliberate practice, regardless of their disability or ability. These bodily experiences indicate how people feel about their bodies $^{12}$, which represent our active vehicle for being in the world and inform the body's intentionality ${ }^{13}$. Hence, the human motor function must be considered not solely from the point of view of physical education, sport, or rehabilitation, as this is an entirely philosophical issue ${ }^{11}$. As it can be deduced from Edmund Husserl's thought in his famous Ideas $\mathrm{II}^{14}$, a seminal work not only for Merleau-Ponty's philosophy ${ }^{15}$ but for all bodily phenomenology, body movement is an ontological condition for experience in the world.

In this article, we examine through first-person reports, how the experiences of athletes with physical disabilities in integrated participation with people without disabilities in mainstream sports occur. In this way, it will be possible to understand, according to the experience of athletes with a physical disability, how the others are perceived by them and how they perceive the others regard them during integrated sports practice, how they overcome their difficulties, perception of their own body and how it can change according to their engagement with mainstream sport. Such information can be essential for transforming a look that downgrades, focused only on the disability, to a look and treatment that value the person, his capacity, what he can perform in his condition of disability.

\section{Methods}

\section{Participants}

The intentional sample included six athletes with some type of physical disability (Table 1) from various cities in the state of São Paulo, Brazil, who should fulfill the following criteria: (a) at least one year practicing the sport and (b) participation in no less than one local, regional, or state mainstream competition since these minimum factual criteria infer they practice or practiced the sport regularly and effectively alongside people without disabilities. The contacts took place from an intentional process, in which the link with the interviewees was sought from teams or groups that practiced sports without any type of adaptation for people with disabilities. The interviews were carried out after signing the Free and Informed Consent Term, according to the ethical requirements for this type of research approved by the Faculty of Philosophy, Sciences and Letters at Ribeirão Preto Ethics in Research Committee (CAAE: 24855014.8.0000.5407).

\section{Phenomenological interview}

The phenomenological interview was adopted to access the experiences of athletes with physical disabilities in mainstream sports. The perspective adopted in the present study was that of the classical phenomenology of Husserl ${ }^{14}$ and authors accordant with the phenomenology proposed by this philosopher.

According to Martínková and Parry ${ }^{16}$, phenomenology is a research method that seeks to identify structures of consciousness that try to account for how something is experienced by someone, an investigation of experiences

Table 1 - Interviewee characteristics.

\begin{tabular}{lccccc}
\hline Pseudonym & Age & Occupation & Disability & Sport & Competition \\
\hline Michael & 27 & Retired & Cerebellar ataxia & Soccer & Local \\
James & 26 & Industrial designer & Impaired passive range of movement & Karate & Regional Games \\
Cesar & 31 & University student/ Librarian & Impaired muscle power & Swimming & University Games \\
Addison & 32 & Nursing technician & Limb deficiency & Capoeira & Regional Games \\
George & 22 & University student & Limb deficiency & Basketball & Regional Games \\
Keila & 21 & University student & Impaired passive range of movement & Athletics & National championship \\
\hline
\end{tabular}


"as they are presented to the subjects who are having the experiences"10 (p. 37). In addition, Halák, Jirásek, and $\mathrm{Nesti}^{17}$ elucidate that there is a phenomenon from the point of view of phenomenology "when the thing shows itself as what it is" (p. 118). In this case, it asks about the nature of what is experienced by athletes with physical disabilities and the various ways in which their experiences in mainstream sports can appear to us.

The phenomenological interview is one of the fundamental elements of this methodology ${ }^{18}$ through the understanding of the individual from the development of a sensitive listening ${ }^{19}$. According to Barreira ${ }^{18}$, a significant characteristic of the method is the epoché, in which it is intended to suspend the belief of the natural attitude, by subtracting from the intentional scene the use of our previous knowledge when we analyze a phenomenological phenomenon, whether scientific, cultural or common sense $^{18}$. Furthermore, all interview processes are characterized by deepening with the experience of people, that is, they aim to favor the interviewee to verify the lived experiences ${ }^{18}$.

The number of interviews was limited based on saturation, i.e., when there was a systematic repetition of the meanings expressed in the reports. Moreover, the identities of the interviewees were replaced by pseudonyms, to prevent identification. Although the interviews were manually transcribed in full in Portuguese, we chose to translate only the excerpts used in this study into English. In addition, we adopted the back-translation procedure described by Mandal ${ }^{20}$ in order to ensure transparency and reliability when transmitting the original native meanings.

Barreira and Ranieri ${ }^{21}$ and Barreira ${ }^{18}$ explain that the questions used in the phenomenological interview are guiding questions, and from them, other questions arise that aim to lead the interviewee to the experience in order not to be limited to the superficial. The questions are exploratory in nature, being open-ended questions that lead the interviewee to think about and get back in touch with their experiences so that the authentic or original speech is expressed. According to Amatuzzi ${ }^{19}$, authentic or original speech is the first speech pronounced with meaning, a language that expresses thoughts which can be resumed in the derived empirical language, whereas in the second language, although at times complex, nothing new is brought, without requiring any effort of expression, like the ordinary, everyday language.

The script prepared for the semi-structured interview, aiming to direct each interviewee to get in touch and express their own experiences, consisted of the following questions: 1) How did sport appear in your life? 2) How does your disability appear during training/competition? 3) What is the meaning of sport in your life? 4) Do you think that sports have transformed the way you see your disability? How?
Question 1 seeks to lead the interviewee to trace a history of the sporting practice experienced so far. Question 2 examines experiences about how the disability is perceived by the participants and other people during sports practice. Question 3 investigates experiences offered by participation in mainstream sports according to the practitioners. Question 4 deals with a possible change in the interviewee's view of his disability through mainstream sports.

\section{Data analysis}

With the set of interviews in hand, i.e., recorded, and transcribed, the eidetic analysis takes place, which focuses exclusively on the relationship between the object of the experience and the experience of that same object. Giorgi and Sousa ${ }^{22}$ elucidate that the eidetic analysis seeks to establish the "essence" of the object of study, through imaginative free variation, which seeks multiple manifestations of a phenomenon to describe it in what is essential to it $^{18,21}$, defining syntheses of psychological meanings on the subject. Finally, the significant experiences are intentionally crossed, i.e., the essential elements of the experiences present in the reports are sought, constituting the phenomenological reduction, which allows the creation of categories that reveal structuring experiences of these individuals' experience ${ }^{18,21}$. Hence, the meaning of an experience is expressed through phenomenological reduction as the essential components of the phenomena are addressed $^{18,21}$.

According to a previous study, a key element of the classic phenomenological method based on Husserl's philosophy is the phenomenological reduction ${ }^{18}$. Husserl's phenomenological conception has the situational context of a phenomenon (natural orientation) as a starting point and along with the reductions (phenomenological orientation), it reaches essential elements, the residue of what was subtracted from the reports, unveiling lived structural experiences of the triggered phenomena. In this case, it explains the meaning of what is experienced by athletes with physical disabilities in mainstream sports.

\section{Results}

The initial analysis of the interviews consisted of identifying the significant sporting experiences, as well as understanding the dynamics of the experiences lived by these athletes with disabilities in mainstream sports. From the analysis of the interviews, the significant experiences were intentionally crossed, i.e., the essential elements of the experiences present in the reports were sought through phenomenological reduction. Five categories were built from the interviews, highlighting relevant aspects of these individual experiences: operational body barred in the world; shaping the movement; the invisibility of disability; 
determination stimulus; and normalization of social relations in mainstream sport.

\section{Operational body barred in the world}

The first significant elements of the interviewees' experiences appear at times when the doubt about the possibility of making certain movements is raised by others. Likewise, the participants also perceive the impossibility of performing some movements similarly to people without disabilities, as stated by Cesar: "How can I compete in handball against those giant horses in a wheelchair? It doesn't work". In most cases, it can be noted that the sportsman with a disability faces barriers to opportunities to become familiar with sports planned for people without disabilities. It resembles a diminishing experience, which apparently begins with the looks of strangers and is likely to become the person's perception. Some excerpts highlight excessive care, as in James's case: "My mother was afraid to let me do karate because of my disability". Being the target of derogatory attitudes also marks the participants' experiences, as in Michael's experience: "It was common to hear things like "leave this one unmarked because he won't do anything", and Cesar: "People usually think that a person with a physical disability is also intellectually disabled, deaf, blind. Some people come to me talking like I'm 7'. The way these athletes are viewed also reflects a perception of distrust, as noted in Addison's speech: "I was introduced as a graduated teacher, and then I heard someone who was there saying 'is that so?"'. Likewise, George reported: "When people see me, they look scared and say, "hey, how's this guy going to play?". As will be discussed later, the perception of normality experienced by athletes with physical disabilities will be central to their own experience. However, participants are frequently confronted with looks and stances accusing their difference as a depreciated abnormality.

\section{Shaping the movement}

Despite the difficulties that arise during sports practice, athletes with disabilities can develop adaptations to participate in mainstream sports. Intense commitment to training sessions, as well as changes in movement execution patterns, represent strategies that may allow them to be more competitive, without utilizing elements outside the rules. This is observed in James's speech, who developed a different posture pattern for practicing karate:

\footnotetext{
"My disability is in my right arm, and I find it easy to use my legs. Since my right hand cannot be extended or raised for a long time, I use my left hand in the front to try to obscure this defect" (James).
}

The movements developed by Addison end up being requested in his Capoeira classes: "Sometimes, when I'm teaching in some places, they want me to make my movements, not the ones they do". The same is true of George, who says he can achieve the same goal differently: "In sports, there are things you can do that I won't be able to. But I can do it in a different way, which would be practically the same thing that you would do". Reporting something outside the sports context, Cesar highlighted the perception of how his condition also implied positive differences in daily life, differences that, in a way, demonstrated his efficiency in locomotion due to the wheelchair:

\footnotetext{
"I said to myself: 'wow, I'm walking faster than everyone'. I used to be the first to arrive. This happens to the present day. I don't see myself as a disabled man in a wheelchair, because if you think about it, I walk faster than you do. I don't get tired; I'm sitting all the time. So, you know, I have a comfort that a person who walks doesn't have" (Cesar).
}

\section{Invisibility of disability}

The perception of body effectiveness through a process of invisibility of the disability can be observed in a set of experiences between different reports. This becomes more meaningful with the progression of events that culminate in the acceptance of the disability and the recognition of its self-efficacy.

Michael reports an occasion when his teacher's attitude is brought up as a reference to what is outlined as his moral posture in relation to his disability, valuing his efforts and his willingness to experiment, characteristics that must be appreciated and dignified in a person:

\footnotetext{
"One day in elementary school, a guy who didn't know me laughed at me when the teacher called my name on the roll call. Then, the teacher said, not only for this guy, who laughed, but for everyone: 'If you had half of his effort, it would be great, because even though he has a disability, he tries hard. Even though he can't do something, he tries"' (Michael).
}

James mentions what it is like to be in a competition: "When we are going to compete, we also prepare ourselves so that our opponents do not notice, and they generally do not notice the disability. So, I feel like a person without disabilities". It is noteworthy karate is a combat sport, therefore, it is a type of competition where the opponent tries to benefit directly from any disadvantages that a competitor may present. This occurs in technical, tactical, strategic, and physical terms, not excluding a possible physiological limit.

The body's acceptance appears specially and explicitly in Cesar's experience:

\footnotetext{
"It's one thing to be dressed, and it's another to expose a stunted leg, the hollow of your back. People watching, you feel a little unprotected. So, swimming helped me a lot in this aspect. So, I don't worry if I'm wearing swimming trunks, if I'm wearing pants. I see myself in the mirror and I see myself a lot easier than years ago" (Cesar).
}

Respondents express the importance of not being recognized for their disabilities, but for their sport: "People started seeing me beyond the wheelchair. If you ask 
some people about me, they will tell 'the guy who works at the library' or 'the swimmer"" (Cesar); "When I go out on the street, some people say: 'That guy over there plays basketball"' (George). George also recognizes how competitive he is, as his opponents did not relieve him: "In fact, I was the one who got the hardest hit".

There is a positive value attached to the sporting experience, as shown by Addison's statement:

\footnotetext{
"Sometimes, you think you are less. With Capoeira I saw we are the same. There is no difference. The person puts the limit. But there is no limit. I make some moves thought by many as impossible, but it isn't. It depends on how much effort you put in. So, 'I can't' doesn't exist. If you want, you search and go after it" (Addison).
}

Disabling looks are accompanied by strangeness. As seen in the category operational body barred in the world, the first significant elements of the participants' experiences are related to attitudes described as derogatory. There follows a malaise and the possible constraint of a body seen as impaired by its natural condition. In two interviews, this incorporation of the gaze of others in the object's body appears clearly. Cesar, who talks about the difficulty of seeing himself in the mirror, and Keila, who realized that the withdrawal from sports practice was accompanied by a negative feeling: "It seems that the head is weak. When you are on the street, everyone looks at you in a crooked way". However, the reports converge on a crucial existential change, the transition to a new position. This occurs when the experience in sports gradually shifts the perception of itself from the emphasis on the object body to the emphasis on the subject body, the perception of itself as capable of acting in the world, often objectified as a minor and incapable.

\section{Determination stimulus}

In this category, respondents describe capacity experiences. Recognizing one's own capacity increases self-efficacy, even if there are possible difficulties in mainstream sports. Some participants report having overcome their difficulties by competing only in mainstream sports, as is the case with Michael:

"Even though it is difficult for me, I mean, I walk slowly, I can go wherever I want, alone. I tried proving to myself that I am capable, that I could be better than normal guys. Then, one day I scored a goal" (Michael).

James reports an appreciation of the principles of karate as a stimulus to determination: "The fundamentals of karate make us walk with determination, regardless of the outcome. We can overcome any obstacle, like nervousness or even my disability in the arm. So, in a competition, we try to do what we train, without secrets". Similarly, Cesar says that when he competed against swimmers without disabilities, he felt his sporting experience had been elevated: "In my second year of under gra- duation I competed in swimming. Okay, I didn't win, because I competed against people without disabilities, 'normal' people. Even so, it was a success. Everyone talked about me. I swam and everyone looked". Addison mentions the difficulties he overcame at the beginning of his practice: "In the beginning, I had to work hard. I had to adapt to some movements of balance and strength". The period doing physiotherapy is highlighted by Keila:

"I had to stay like this for a year because I had to undergo surgery and realized my arm atrophied. I said to myself: 'If I don't do physical therapy, I can play sports, and my performance will continue improving.' I realized it would be good for me, not only for my health but for my disability. Physiotherapy is boring, and training, you know, you expend all of your energies" (Keila).

\section{Normalization of social relations in mainstream sport}

This category provides reports of experiences concerning to the politicization of experience in social relations. This politicization is born out of a moral sense that highlights situations in which what is understood as the rights of participation and inclusion of these athletes in distinctive communities, like sports associations and the society as a whole, are hurt. To put it concisely, it is a claim arising from the perception that the institutional barriers to their effective participation in human society are not natural but normative, therefore historical, and political.

It can be hypothesized that these social norms have always aimed to protect and guarantee conditions of justice for people with disabilities. No interviewee shows more of the error of using this method than Keila. According to her account, she was prevented from receiving financial support to compete in conventional athletics, although her results were better than those of several competitors without disabilities:

\footnotetext{
"At that time, the staff in that city no longer wanted me to compete because I was taking money from their athletes. Only three would benefit. This girl was falling behind in fourth or fifth place. Therefore, they filed an appeal so that I no longer compete with them" (Keila).
}

Impediments to participation based on certain differences should not be based on any principle of justice. Opponents' attempts to deny her the right to compete in mainstream sports aimed at maintaining privileges and interests not guided by sporting criteria. Without the moral certainty that what really counts is commitment, that the value is in what someone can do and not in the physical condition, people with disabilities would not practice any sport. This is because these people tend to go through extremely discouraging situations inspired by the objectification of their incapacitating condition as non-competitive. This can be identified in Cesar's speech, which expressed how his disability stands out among strangers: 
"If I am in a bar, it is clear my disability will show up. It will appear first due to the wheelchair, which unfortunately draws more attention. But, if I'm competing if I'm training, it wouldn't happen. Therefore, I am seen as normal. There was no need to highlight the disability" (Cesar).

\section{Discussion}

When people with physical disabilities launch their bodies into a world designed for people without disabilities, barriers arise against them as obstacles to be familiar with the things of the world ${ }^{6}$. This happens due to a perceptual contrast (pre-reflective or not) with the many mundane, physical, and institutional norms, both socially configured. In that manner, the disability condition appears as decreased in terms of chances of action. However, in the face of these adversities, the athletes interviewed adapt, seek ways to remain competitive, positioning themselves in such a way as to point out that what counts is the effort, that there is a greater value than that of the physical condition in what they do and can do with their body condition. Therefore, from the point of view of their experience, these participants do not start from an objective predetermination that informs their mobility as reduced, limited, inefficient, and, eventually, depreciated. Although there is no denial on their part that their condition imposes limits, these limits are not positioned as ready and natural.

The identified categories present distinctions that occur in the layers of the human structure, in the stratification of the experience ${ }^{23}$. The category operational body barred in the world portrays a body dimension on the social plane, where the person is barred by the view of the physical. The following category, shaping the movement, reflects a psychic character intertwined, in the order of bodily conditions, satisfaction, and desires of the person with a disability to identify possibilities and test, by trial and error, and to achieve a competitive standard. As for the invisibility of the disability, a social aspect shows that the individual is no longer impeded, and his ability leads to a loss of focus on the disability. Next, the category stimulus of determination shows a strong spiritual element of that athlete, through the relationship of effort, perseverance, and appreciation of his ability. Finally, the category normalization of social relations in mainstream sport concerns the political aspects of standardization, guaranteeing the participation rights of people with disabilities.

Considering the possibility of analyzing these categories temporally, where each part of the process succeeds the other, the distinction of categories does not suggest separation of experiences and not necessarily a chronology of experience. Each moment emphasizes one aspect of stratification but does not eliminate the other. The experiences of each respondent were inserted in a historical horizon and prejudices were already displayed showing a parallel between the historical and the individual. The political aspects of normalization are already present in the first category, while the spirit of determination can be a struggle for recognition, but it does not mean that it did not exist before, or even a condition that the athlete fights for inclusion. The modeling of the movement involves the stimulation of determination, still somewhat under construction

The experience referred to as "operational body barred in the world" appears through looks and postures directed at the object body that accuse physical differences as a depreciated abnormality. According to the work of Nenon ${ }^{14}$, Husserl states in his post mortem Ideas II that the body is both subject and object. On the one hand, as a subject, the body is experienced as the proper and inalienable means by which the "self" acts in the world. On the other hand, as an object, the body itself is perceived as a body among other bodies in the world. What differentiates it from other bodies is, fundamentally, its sensitive condition and subject agent. The look of the other corresponds to a relevant (intersubjective) facet of the constitution of the personal perception of the body itself as an object ${ }^{24}$. The intersubjective sharing of appraisals allows the social way in which the body is appreciated participating in the perception of itself.

Attitudes and looks of others accompanied by an estrangement qualified as derogatory are frequently experienced in mainstream schools, for example, where students with disabilities share an integrated environment with peers without disabilities. In their literature review, Nabaskues-Lasheras et al. ${ }^{25}$ demonstrated that along with gender, sexuality, social class, and ethnicity, disability was identified as a determining factor for students to be recognized as capable of meeting the expectations of specific bodily performances by their physical education teachers, who commonly reproduce discourses that suggest that students with disabilities must be excluded or exercise peripheral positions in physical education classes. Consequently, students with disabilities resist derogatory speech that makes their bodies inferior by trying to pass themselves off as people without disabilities ${ }^{26}$. In addition, Swartz and colleagues ${ }^{27}$ point out that, according to the experience of Paralympic athletes who only compete with athletes with disabilities, it is also common for people with disabilities to reproduce derogatory stereotypes of the body.

The experience of "shaping the movement" refers to the emphasis placed on the body scheme, on the active and operative performance of the body in response to the environment, and not on the body image. Gallagher ${ }^{29}$ elucidates that "the body schema operates in a non-conscious manner" (p. 552), while in the body image the individual experiences some sort of awareness of the body. As argued by Salamon-Krakowska ${ }^{11}$, during sports practice, the person does not think about the movement but interacts with 
the objects disposed of. Epiphanio and Matos ${ }^{28}$ demonstrate that to reach a competitive performance level, mastering the movements of the sport practiced will be one of the most critical challenges to be overcome by athletes with disabilities. Consequently, the body scheme will be decisive for body image, positively modified from a scheme that no longer operates in the limitation register, but in the potency register ${ }^{29}$. Therefore, however challenging the learning and improvement of sports gestures may be, athletes with physical disabilities learn to organize and integrate their bodily experience, which consequently allows them to perform actions in a different way to achieve a similar goal as someone without physical limitations $^{30,31}$.

It can be stated that high-performance sport deals all the time with the objectification of the disadvantage. This does not mean that lack of ability in sports practice can be attributed to a person with a disability. DePauw ${ }^{1}$ argues that the concept of "being an athlete" and the way the sports body has seen need to be redefined, an argument that agrees with that of Martínkóva ${ }^{32}$, for whom the "various alleged truths about the body, health, movement, exercise, physical education and sports" (p. 64) should be reconsidered. Consequently, if such redefinitions are accompanied by the respective changes in perception, it is possible, for example, that soccer players or Capoeira fighters who have a disability, as in the cases of Michael and Addison, respectively, are not subject to negative comments or evoke doubts about their ability to compete in their sports.

The reports of some interviewees demonstrate that there was no significant degree of competitiveness in their performance in mainstream sports. These are the cases of Michael, who reported the option of not playing more difficult matches, and Cesar, who although being acclaimed in the swimming event at the University Games, did not achieve a prominent position. Moreover, the athletes interviewed exposed an effective limit on their body condition in relation to high-performance sports in certain conventional modalities. That is Cesar's experience, who refers to the conflict between body and wheelchair limiting him to participate in the handball competition at the University Games. Another limiting point is reported by Kitchin and Howe $^{33}$, who verified that there is a tendency for only extremely skilled athletes with disabilities to succeed in mainstream sport, as is the case with Natalia Partyka and Oscar Pistorius. In addition, athletes with disabilities will have fewer opportunities to participate in mainstream sport if the team or club they belong to is lacking in resources and support ${ }^{35}$.

Nonetheless, even if their performance may not achieve significant results - which, in fact, is common to most defeated athletes in any sport - integrated participation may bring several benefits to the athlete with a disability. Mayoh and Jones ${ }^{36}$ point out that their sporting experiences may allow them to experience their bodies in valuable ways, directing the attention from the disability to what they do, an appreciation of the person. As reported by some of the interviewees, there is a change in the attitude of the other towards them as they experience situations in which they are recognized as the "boy of swimming", or the "boy who plays basketball." This is in line with what is presented by Wilhite and Shank ${ }^{37}$ and by Woodmansee and colleagues ${ }^{38}$, who verified an intensification of the bonds of friendship between people with and without disabilities, in addition to increased confidence and a feeling of comfort by the players with disabilities for being in an integrated environment. In addition, as they gain prominence in competitions, athletes with disabilities report an experience of autonomy and independence ${ }^{28}$, and the perception that the public's focus changes from disability to proficiency in activities they were initially not expected to be capable of performing ${ }^{39}$.

When analyzing athletes with disabilities that competed in Paralympic sports, several positive experiences are also pointed out. This is the case of the work conducted by Swartz et al. ${ }^{27}$, where Paralympic athletes reported participation in competitions a facilitating context for understanding their disability and reformulating their identities, as well as Pack et al. ${ }^{39}$, who verified through the reports of Paralympic swimming athletes the experience of improving their personal and social identity, the development of a career plan and acting prospects after they retired from competitions. Moreover, the creation of new categories, i.e., adapted sports, or initiatives that provide the reverse integration through programs in which people without disabilities are integrated into sports created or adapted for people with disabilities ${ }^{40}$, may lead to a change of vision, perceived as competitive and fair by practitioners, which not only provides adaptations in physical activities for people with disabilities but all people ${ }^{41}$.

On the other hand, the experiences of some of the interviewees confirm that, eventually, they manage to be competitive in their sports. These are the cases of James, who competes in karate as equals in mainstream tournaments without at least his opponents realizing the difficulty imposed by a limitation that restricts the movements of his right arm; George, who even without a fully developed right forearm, plays basketball better than many opponents without disabilities; Addison, who graduated as a Capoeira teacher; and what about Keila, who gets to qualify better than her opponents without disabilities reaching an index to obtain financial assistance from the practice of mainstream athletics?

The highlight obtained by these athletes meets the need to overcome the vision that naturalizes the disability. As pointed out by Ricoeur ${ }^{2}$, from the philosophy of the physician and philosopher Georges Cangilhem (19941911), there is a change in the biological norm with regard to people with disabilities - from the least (disability as 
negative, as a minor) to the most (new rules, another organization, different). It can be mentioned that, in this perspective, this condition is seen as another way of being in the world. This is a way in which people with disabilities can, if not achieve the same goals as people without disabilities, at least orient themselves differently in the world, a way that does not always guarantee equivalence in competitiveness in the context of sports.

Athletes with disabilities may also seek equivalence in competitiveness through technological artifacts, such as innovative prostheses, which apparently help to transform people with disabilities into "normal" individuals ${ }^{42}$. This is the case of Oscar Pistorius, to whom the desire to participate in a conventional competition was surrounded by controversy ${ }^{8}$. Richard et al. ${ }^{8}$ argue that these controversies pointed much more to the fact that the use of modern carbon fiber prostheses could generate a super capacity that would guarantee advantages during the dispute. This refers to a stimulus to integrated sports practices that value justice and fair participation of people with disabilities among people without disabilities. According to Van Hilvoorde and Landeweerd" ${ }^{6}$, "justice is seen as being independent of luck and favoring a more equal distribution of harms and benefits" (p. 2223). Fundamentally, the issue of the integrated practice of people with disabilities with people without disabilities will always incite doubt, questioning, and, eventually, surprise about one of the crucial and constitutive issues of sport: fair competition.

Sande $l^{42}$ argues from this thought by saying that not all innovations in equipment for the adaptation of people with physical disabilities corrupt the sportsmanship, so that, therefore, they are likely to compete fairly with individuals without disabilities. Several methods allow athletes to benefit from sports, such as specific drugs to gain strength and endurance, training in "altitude houses" in order to increase the production of red blood cells, and even genetic improvement, which the issue of justice in sports disputes gains ample magnitude ${ }^{42}$. Van Hilvoorde and Landeweerd ${ }^{6}$ state that elite athletes who choose not to use substances that increase performance can, in their way, become "disable" in a context where doping is "normalized", that is, despite being illegal, be widespread among competitive sportspeople. The question that Sandel $^{42}$ poses, and which is pertinent to the problematization presented here, is: "Do equipment innovations improve or obscure the essential skills for competition?" (p. 43).

Some elements must be extracted from this set of reports to recognizing the experiential conditions that constitute ontologically the transition to a new position: the recognition that occurs in social relations. These athletes frequently manage conflict as the claim of what they are entitled to, such as when they are prevented from doing something, as in the case of Keila, who was prevented from receiving financial aid for ranking among the best. In addition, the struggle for recognition also concerns what appears in experiences of overzealousness and depreciation for the other, as when they are regarded as children, as people with intellectual disabilities, or in some way inferior. There is a constant experience of derogatory strangeness that others have in their first contact with the athlete with a disability and that later becomes an appreciative surprise. The recognition here happens as an effect of an ethical positioning (of the interviewed athletes) and repositioning (social, by others) in the inter-subjective relationships.

As pointed out by Paterson and Hughes 9 , the person with a disability who is prevented from contributing socially suffers a type of discrimination that concerns a segregationist position. The socio-moral experiences present in the category normalization of social relations in mainstream sport, are those that authorize the use of articulation with the struggle for recognition in the sphere of rights. As stated in Honneth's work ${ }^{43}$, "the importance of rights for self-respect lies in the fact that rights ensure the real opportunity to exercise the universal capacity constitutive of personhood" (p. xv). Merits (qualities) are no longer stated as a condition for respect, but as elements to be considered, individualizing (singularizing) the respect when in the concreteness. Therefore, it is important to reconsider the defense of the ideals of law that are considered principles of our society, giving more public appearance to capacity than to the appearance of disability.

In summary, people with physical disabilities who train and compete in mainstream sports, in an integrated manner, initially faces an estrangement that comes from the other's gaze, distrust of their ability, and, sometimes, excessive care that refers to the fear that they may suffer some kind of damage. Their involvement in such practices enables them to experience a feeling of capacity that leads to a perception of normality that is essential to their experience, where the disability becomes invisible by the performance of effective movements and competitiveness. Consequently, disability is better accepted by the individual in a process of esteem and recognition that affirms the person more than their physical condition. To do so, it is necessary to address issues of justice, the desires of these athletes, and objective limits that modify the questions of fairness. Although the disability imposes undeniable limits, it is nevertheless possible that some of them obtain great sports performance and wish to compete against people without disabilities, and even if they are not highly competitive, integrated participation ends up showing the individual's moral socialization, which can lead to an expansion in the relations of recognition, as well as gains in self-respect and respect. 


\section{Conclusion}

The purpose of this study was to analyze and understand the experience of athletes with physical disabilities who have already competed in an integrated context among athletes without disabilities. It is important to emphasize that these findings are characteristic of a group of individuals who present mild and moderate disabilities in addition to being successful in relation to access to integrated sports practices. The interviewees' reports indicate that the experience in mainstream sports allowed them to feel "comfortable in their own skin", by improving their experience of capacity, self-efficacy, and recognition through the mutuality between self-perception and the expectation of acceptance by society.

\section{Acknowledgments}

The authors would like to thank the participants of this study as well as the National Council of Scientific and Technological Development (CNPq) (process 2013.1.396.90.1) for financial support. Cristiano Roque Antunes Barreira's contributions to the writing of this article are the result of research supported by the São Paulo Research Foundation (FAPESP), grant \# 2019/11527-6.

\section{References}

1. Depauw KP. The (1n) Visibility of DisAbility : Cultural Contexts and "Sporting Bodies." 2012;6297. doi:10.1080/ 00336297.1997 .10484258

2. Ricoeur P. A diferença entre o normal e o patológico como fonte de respeito. In: O Justo 2: Justiça e Verdade e Outros Estudos. São Paulo: WMF Martins Fontes; 2008:210-20.

3. Kamberidou I, Bonias A, Patsantaras N. Sport As a Means of Inclusion and Integration for "Those of Us With Disabilities." Eur J Phys Educ Sport Sci Open Access Publ Gr. 2019;5(12):99-128. doi:10.5281/zenodo.3464696

4. Sassaki RK. Inclusão: Construindo Uma Sociedade Para Todos. 7th ed. Rio de Janeiro: WVA; 2006.

5. Swain J, French S. Towards an Affirmation Model of Disability. Disabil Soc. 2000;15(4):569-82. doi:10.1080/ 09687590050058189

6. Van Hilvoorde I, Landeweerd L. Enhancing disabilities: Transhumanism under the veil of inclusion? Disabil Rehabil. 2010;32(26):2222-7. doi:10.3109/ 09638288.2010.491578

7. Jurczak A, Spieszny M, Görner K, Jenek B, Wójcik K. Sports and Other Forms of Physical Activity in the Rehabilitation of the Disabled. J Phys Educ Heal Soc Perspect. 2018;7(12):49-57.

8. Richard R, Issanchou D, Ferez S. Fairness, Regulation of Technology and Enhanced Human: A Comparative Analysis of the Pistorius Case and the Cybathlon. Sport Ethics Philos. 2020:1-15. doi:10.1080/17511321.2020.1818278

9. Hughes B, Paterson K. The Social Model of Disability and the Disappearing Body : Towards a sociology of impair- ment. Disabil Soc. 1997;12(3):325-40. doi:10.1080/ 09687599727209

10. Standal ØF. Phenomenology and adapted physical activity: Philosophy and professional practice. Adapt Phys Act Q. 2014;31(1):35-48. doi:10.1123/apaq.2012-0064

11. Salamon-Krakowska K. Fenomenologiczne studium motoryki ciała. Fizjoterapia. 2012;20(1):71-8. doi:10.2478/ v10109-012-0006-1

12. Paterson K, Hughes B. Disability Studies and Phenomenology: The carnal politics of everyday life. Disabil Soc. 1999;14(5):597-610. doi:10.1080/09687599925966

13. Swain J. Disability studies: an interdisciplinary introduction. Disabil Soc. 2011;26(4):503-5. doi:10.1080/ 09687599.2011.567809

14. Nenon T EL. Edmund Husserl's Contribution to phenomenology of the body in Ideas II. In: Issues in Husserl's Ideas II. Dordrecht: Kluwer Academic Publishers; 1996.

15. Merleau-Ponty M. Phenomenology of Perception. Delhi: Motilal Banarsidass Publishers; 1996.

16. Martínková I, Parry J. An introduction to the phenomenological study of sport. Sport Ethics Philos. 2011;5(3):185201. doi:10.1080/17511321.2011.602571

17. Halák J, Jirásek I, Nesti MS. Phenomenology is not phenomenalism. Is there such a thing as phenomenology of sport? Acta Gymnica. 2014;44(2):117-29. doi:10.5507/ ag.2014.012

18. Barreira CRA. Análise fenomenológica aplicada à psicologia: recursos operacionais para a pesquisa empírica. In: Mahfoud M, Savian Filho J, eds. Diálogos Com Edith Stein: Filosofia, Psicologia, Educação. São Paulo: Paulus; 2017:317-68.

19. Amatuzzi MM. Por Uma Psicologia Mais Humana. Campinas: Alínea; 2001.

20. Mandal PC. Translation in Qualitative Studies: Evaluation Criteria and Equivalence. Qual Rep. 2018;23(10):2529.

21. Barreira CRA, Ranieri LP. Aplicação de contribuições de Edith Stein à sistematização de pesquisa fenomenológica em psicologia: a entrevista como fonte de vivencias. In: Mahfoud M, Massimi M, eds. Edith Stein e a Psicologia: Teoria e Pesquisa. 1st ed. Belo Horizonte: Artesã Editora; 2013:449-66.

22. Giorgi A, Sousa D. Método Fenomenológico de Investigação Em Psicologia. Lisboa: Fim de século; 2010.

23. Ales Bello A. The Language of Our Living Body. Tymieniecka A-T, ed. Analecta Husserliana. 2006;LXXXIX:3-14. doi:10.1007/1-4020-3707-4_1

24. Barreira CRA. Da história da fenomenologia à ética na psicologia: tributo ao centenário de Filosofia como Ciência Rigorosa (1911) de Edmund Husserl. Memorandum. 2011;20:135-44.

25. Nabaskues-Lasheras I, Usabiaga O, Lozano-Sufrategui L, Drew KJ, Standal ØF. Sociocultural processes of ability in Physical Education and Physical Education Teacher Education: A systematic review. Eur Phys Educ Rev. 2020;26 (4):865-84. doi:10.1177/1356336X19891752

26. Amsterdam N Van, Knoppers A, Jongmans M, Jongmans M. 'It's actually very normal that I'm different'. How physically disabled youth discursively construct and position their body/self. Sport Educ Soc. 2015;20(2):152-70. doi:10.1080/13573322.2012.749784 
27. Swartz L, Bantjes J, Knight B, Wilmot G, Derman W. "They don't understand that we also exist": South African participants in competitive disability sport and the politics of identity. Disabil Rehabil. 2016;40(1):35-41. doi:10.1080/ 09638288.2016.1242171

28. Epiphanio EH, Matos E. O sentido do esporte para atletas com e sem deficiência: uma compreensão fenomenológica. Rev Bras Psicol do Esporte. 2017;7(1):76-91.

29. Gallagher S. Body image and body schema: A conceptual clarification. J Mind Behav. 1986:541-54.

30. Hogeveen B. Skilled Coping And Sport: Promises Of Phenomenology. Sport Ethics Philos. 2011;5(3):245-55. doi:10.1080/17511321.2011.602575

31. Block BA, Weatherford GM. Embodied Identities : Using Kinesiology Programming Methods to Diminish the Hegemony of the Normal. Quest. 2013;65(31):31-43. doi:10.1080/00336297.2012.727370

32. Martínková I. Jan Patočka's three movements of human life with respect to physical education and sport practice. Acta Univ Palacki Olomuc Gymnica. 2006;36(2):59-66.

33. Kitchin PJ, Howe PD. The mainstreaming of disability cricket in England and Wales: Integration 'One Game' at a time. Sport Manag Rev. 2014;17(1):65-77. doi:10.1016/j. smr.2013.05.003

34. Jeanes R, Spaaij R, Magee J, Farquharson K, Gorman S, Lusher D. 'Yes we are inclusive': Examining provision for young people with disabilities in community sport clubs. Sport Manag Rev. 2018;21(1):38-50. doi:10.1016/j. smr.2017.04.001

35. Kitchin PJ, Crossin A. Understanding which dimensions of organisational capacity support the vertical integration of disability football clubs. Manag Sport Leis. 2018;23(1):2847.

36. Mayoh J, Jones I. Making well-being an experiential possibility: the role of sport. Qual Res Sport Exerc Heal. 2015;7 (2):235-52. doi:10.1080/2159676X.2014.893901

37. Wilhite B, Shank J. In praise of sport: Promoting sport participation as a mechanism of health among persons with a disability. Disabil Health J. 2009;2(3):116-27. doi:10.1016/ j.dhjo.2009.01.002
38. Woodmansee C, Hahne A, Imms C, Shields N. Comparing participation in physical recreation activities between children with disability and children with typical development: A secondary analysis of matched data. Res Dev Disabil. 2016;49-50:268-76. doi:10.1016/j.ridd.2015.12.004

39. Pack S, Kelly S, Arvinen-barrow M. "I think I became a swimmer rather than just someone with a disability swimming up and down :" paralympic athletes perceptions of self and identity development. Disab and Rehab. 2017;39:206370. doi:10.1080/09638288.2016.1217074

40. Spencer-Cavaliere N, Peers D. "What's the Difference?" women's wheelchair basketball, reverse integration, and the question(ing) of disability. Adapt Phys Act Q. 2011;28 (4):291-309. doi:10.1123/apaq.28.4.291

41. Geidne S, Jerlinder K. How sports clubs include children and adolescents with disabilities in their activities. A systematic search of peer-reviewed articles. Sport Sci Rev. 2016;XXV(1):29-52. doi:10.1515/ssr-2016-0002

42. Sandel MJ. Contra a Perfeição: Ética Na Era Da Engenharia Genética. 1st ed. Rio de Janeiro: Civilização Brasileira; 2013.

43. Anderson JH. Translator's Introduction. In: Honneth A, ed. The Struggle for Recognition: The Moral Grammar of Social Conflicts. Cambridge: MIT Press; 1995:xii-xxi.

\section{Corresponding author}

Jônatas Augusto Cursiol. Av. Bandeirantes 3900, Vila Monte Alegre, 14040-907, Ribeirão Preto, SP, Brasil. E-mail: joe_a_c@hotmail.com.

Manuscript received on March 25, 2021

Manuscript accepted on July 7, 2021

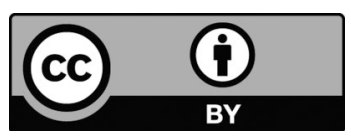

Motriz. The Journal of Physical Education. UNESP. Rio Claro, SP, Brazil - eISSN: 1980-6574 - under a license Creative Commons - Version 4.0 